\title{
Evaluation of Electrochemical Treatment of Chloride Contaminated Mortar Containing GGBS
}

\author{
Ki Hong Lee, Young Hee Jung, Jun Pil Hwang, and Jong Sung Sim \\ Department of Civil and Environmental Engineering, Hanyang University, Ansan 15588, Republic of Korea \\ Correspondence should be addressed to Jong Sung Sim; jssim@hanyang.ac.kr
}

Received 29 March 2017; Accepted 18 June 2017; Published 8 August 2017

Academic Editor: Xiao-Jian Gao

Copyright (C) $2017 \mathrm{Ki}$ Hong Lee et al. This is an open access article distributed under the Creative Commons Attribution License, which permits unrestricted use, distribution, and reproduction in any medium, provided the original work is properly cited.

\begin{abstract}
The present study concerns the influence of cementitious binder on electrochemical treatment of steel embedded in salt contaminated mortar. As binder, ordinary Portland cement (OPC) and ground granulated blast furnace slag (GGBS) were used and the current density of $250-750 \mathrm{~mA} / \mathrm{m}^{2}$ was applied for 4 weeks to complete electrochemical chloride extraction. To evaluate the effect of electrochemical treatment the chloride profile and corrosion behaviour covering chloride concentration, galvanic current density, linear polarization resistance, open circuit potential, and mass loss were measured. An increase in the applied direct current density resulted in a decrease in the chloride concentration at the vicinity of steel, accompanying the mitigated corrosion damage. The performance of electrochemical treatment was more remarkable in mortar containing GGBS presumably due to binding mechanism. However, corrosion damage was more detrimental in GGBS rather than OPC at a given potential, while GGBS had superior corrosion resistance to a corrosive environment and treatment conditions. Therefore, the electrochemical treatment should be conducted prudently to evaluate the corrosion state of embedded steel depending on binder type.
\end{abstract}

\section{Introduction}

Chloride ions in steel reinforced concrete structure have been considered as the most aggressive factor of degradation process associated with steel corrosion, thereby leading to reduction in structural serviceability. To improve the corrosion resistance in terms of high resistivity to deteriorating mass ingress, ordinary Portland cement (OPC) blending with supplementary cement such as granulated blast furnace slag (GGBS) and pulverized fuel ash (PFA) was widely used [1, 2]. As compared with OPC concrete, this blending cement concrete generally has lower diffusion coefficient, resulting from lower connectivity with small capillary pores $[3,4]$ and higher binding capacity $[5,6]$. As to the chemical resistance of these materials to the steel interface on which the corrosive agents accumulate, the lower buffering capacity to prevent $\mathrm{pH}$ reduction at steel surface has been reported [7]. To enhance the direct corrosion resistance of the concrete made with the pozzolanic materials after long term degradation proceeds, few researches according to the electrochemical chloride extraction treatment for concrete made with supplementary cements have been performed [8]. The impact of electrochemical treatment on ensuring better performance of concrete structure submitted to corrosive environment has been first issued in the 1970s [9] and later used to investigate its influence on interface of steel-cement matrix properties in terms of bond strength [10] and formulation of hydration products [11]. However, it is still ambiguous as to whether the addition of pozzolanic materials in concrete is beneficial when electrochemical chloride extraction treatment is applied to the materials contaminated with chloride ions.

In the present study, the influence of binder types, consisting of sole OPC and blending cement with GGBS, on the removal of initially contained chlorides from the inside of steel reinforced mortars and the resultant corrosion rehabilitation was evaluated by measuring polarization resistance and corrosion potential under variation of cathodic current densities between 250 and $750 \mathrm{~mA} / \mathrm{m}^{2}$. Simultaneously, the amount of corrosion products was determined by measuring mass loss of corroded steel in order to find the relationships between cathode current density and rate of corrosion process. From these works, it was possible to determine the corrosion resistance of GGBS based cementitious material 


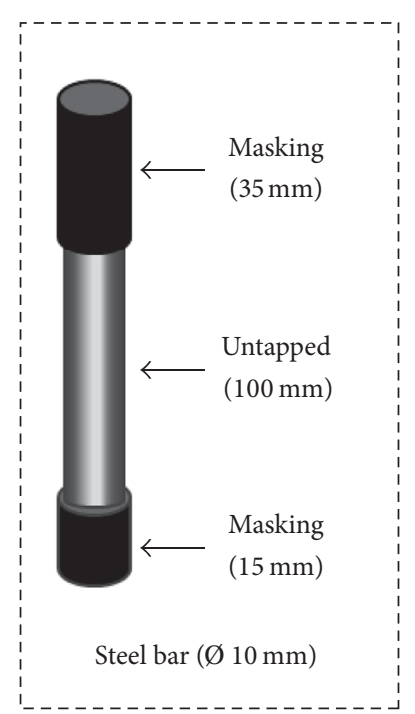

(a) Specification of steel

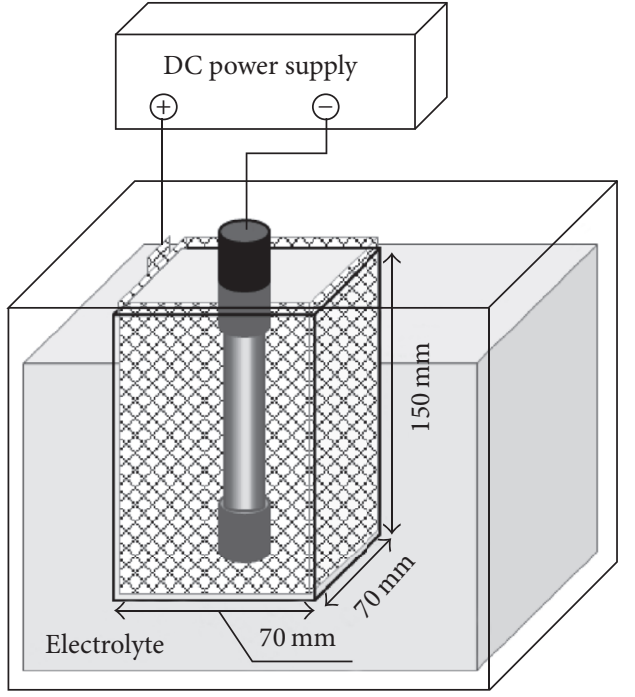

(b) Electrochemical treatment



(c) Electrochemical measurement

FIGURE 1: Schematic for steel (a), electrochemical chloride extraction of concrete (b), and electrochemical measurement of corrosion behaviour (c).

TABLE 1: Oxide composition of binders.

\begin{tabular}{lcccccccccc}
\hline & $\mathrm{CaO}$ & $\mathrm{SiO}_{2}$ & $\mathrm{Al}_{2} \mathrm{O}_{3}$ & $\mathrm{Fe}_{2} \mathrm{O}_{3}$ & $\mathrm{MgO}$ & $\mathrm{Na}_{2} \mathrm{O}$ & $\mathrm{K}_{2} \mathrm{O}$ & $\mathrm{Mn}_{2} \mathrm{O}_{3}$ & $\mathrm{Ti}_{2} \mathrm{O}_{3}$ & $\mathrm{SO}_{3}$ \\
\hline OPC & 64.7 & 20.70 & 4.60 & 3.00 & 1.00 & 0.13 & 0.65 & - & - & 3.00 \\
GGBS & 41.20 & 34.20 & 11.70 & 1.43 & 8.81 & 0.29 & 0.31 & 0.30 & 0.58 & - \\
\hline
\end{tabular}

TABLE 2: Mortar mix proportion for the experimental works.

\begin{tabular}{lccccc}
\hline \multicolumn{5}{c}{ Unit weight $\left(\mathrm{kg} / \mathrm{m}^{3}\right)$} \\
& Cement & GGBS & Water & Sand & Air content (\%) \\
\hline OPC & 557 & - & 251 & 1394 & \multirow{2}{*}{$3.1-4.5$} \\
GGBS & 221 & 332 & 249 & 1383 & \\
\hline
\end{tabular}

under variation of cathodic current densities and to assess its efficiency of enhancing the durability by cathodic protection.

\section{Experimental Work}

2.1. Specimen Preparation. The binder types used in this study are OPC and GGBS where the oxide composition is given in Table 1. The mix proportion of the mortar specimens used in this study was shown in Table 2 in which $\mathrm{NaCl}$ solution was used as mixing water to maintain the initial chloride content, $3.0 \%$ of chlorides by weight of binder. Mortar specimens were cast with a centrally located steel bar, masked on the ends by cement rich paste to prevent corrosion under masking materials, in a $70 \mathrm{~mm} \times 70 \mathrm{~mm} \times 150 \mathrm{~mm}$ cube mould as seen in Figure 1. The mortar specimens were demoulded after $24 \mathrm{~h}$ and then wrapped in a polythene film to avoid leaching out of chemical components or intrusion of aggressive ions into specimens. After 56 days of curing in a chamber at $20 \pm 2^{\circ} \mathrm{C}$ was completed, the steel protruded from specimen was connected with wire to compose the electric circuit. The specimens were surrounded with titanium mesh, which was then connected with wire used as an anode. To evaluate the corrosion behaviour and the effect on chloride removal, mortar specimens were fabricated in two groups having four replications for each test. Although both of the groups were dealt equally to the end of electrochemical treatment, one was set up for monitoring galvanic currents after the testing of polarization and crushed to assess a mass loss of steel in a mortar. The initial mass of steel rebar, embedded in mortar specimen belonging to this group, should be measured in advance to calculate the mass difference of steel before/after corrosion. Another was ground to acquire the content of chloride at the vicinity of steel at electrochemical treatment.

Subsequently, a DC current was applied to the embedded steel and the titanium mesh for electrochemical treatment. The specimens were introduced into the electrolyte to help the passage of electrons and the current density applied varied between 250,500 , and $750 \mathrm{~mA} / \mathrm{m}^{2}$ related to surface area of unprotected steel for 28 days. Immediately after electrochemical treatment, the testing of polarization and measurement of open circuit potential were conducted to all the specimens including specimens for the untreated condition.

2.2. Corrosion Behaviour. The polarization resistance and corrosion potential were measured by using potentiostat performing the testing of polarization technique and open circuit potential after electrochemical treatment as seen in Figure 1. The protrusion of steel, targeted at investigating corrosion properties, was connected to the potentiostat as a working 
TABLE 3: Average of chloride contents at steel depth after electrochemical treatment depending on the applied current densities and binder type.

\begin{tabular}{lcccc}
\hline Binder type & \multicolumn{3}{c}{ Chloride content at steel depth (\%, binder) } \\
& Untreated & $250 \mathrm{~mA} / \mathrm{m}^{2}$ & $500 \mathrm{~mA} / \mathrm{m}^{2}$ & 2.08 \\
OPC & 2.92 & 2.16 & 1.84 & 1.93 \\
$60 \%$ GGBS & 3.06 & 1.94 & $\mathrm{~mA} / \mathrm{m}^{2}$ \\
\hline
\end{tabular}

electrode. Meanwhile, the titanium mesh was used for the auxiliary electrode and the standard calomel electrode was placed close to the specimen as the reference electrode. The potential was swept at $\pm 25 \mathrm{mV}$ from the corrosion potential at a low scan rate of $0.1 \mathrm{mV} / \mathrm{s}$. The polarization resistance was derived from the change of current in a linear range when the potential was swept. Hence, the polarization resistance, which is related to corrosion rate of steel, can be calculated by

$$
R_{p}=\left(\frac{\Delta E}{\Delta i}\right)_{\Delta E \rightarrow 0}
$$

where $\Delta E$ is the overpotential meaning a difference between the applied potential and corrosion potential, $\Delta i$ is the current when overpotential is applied to steel, and $R_{p}$ is the polarization resistance.

The current flowing between embedded steel and titanium mesh was monitored every $12 \mathrm{~h}$ by measuring the potential drop across a resistor of $10 \mathrm{k} \Omega$. The galvanic current density was calculated by Ohm's law. Corrosion initiation can be defined as the time at which a sharp increase of current density appears between the steel and the cathode. To measure the mass loss resulting from corrosion of steel rebar, the specimens were split at the end of galvanic cell test after the corrosion initiation of the last specimen occurred. The mass of steel rebar, of which rust was removed by brushing in the Clark solution within $30 \mathrm{~min}$, cleaning in distilled water, and drying, was measured. Then, the mass loss could be calculated by subtracting the weight of steel after removing corrosion from the original weight. Four uncorroded steel rebars were also dealt with the same procedure to compensate the additional mass loss due to application of strong acid solution to the steel surface.

2.3. Chloride Removal at the Vicinity of Steel. Chloride concentration distribution in the mortar samples after cathodic current application were measured to assess the effects of electrochemical treatment on the removal of chloride. The titanium mesh enclosing the specimen was removed to grind the specimen by a diamond-grit plate of $50.0 \mathrm{~mm}$ in the diameter and obtain the dust sample at the point of $28.5 \mathrm{~mm}$ from the surface sequentially. The chloride content at the vicinity of steel was determined by acid soluble extraction using a nitric acid solution, followed by potentiometric titration against silver nitrite.

\section{Results and Discussion}

3.1. Relationship between Chloride Content and Corrosion Initiation. The chloride concentrations in a vicinity of the steel after electrochemical treatment depending on the applied current density and mortar mix are given in Table 3. The chloride contents were measured at $27.0-30.0 \mathrm{~mm}$ due to the limited investigation at $30.0 \mathrm{~mm}$ of cover depth. Although there was a negligible variation between specimens untreated perhaps due to a distribution of aggregate, it is apparent that electrochemical treatment was very effective in removing of chloride ions from steel surface by driving repulsive forces between anions and steel, as the cathode, irrespective of binder type. A reduction of chloride ions was remarkable at only the lowest current density (i.e., $250 \mathrm{~mA} / \mathrm{m}^{2}$ ), while a slight reduction of chloride ions was observed in the case of higher current densities at identical increment of current density. On the other hand, reduced chloride concentrations were always higher in GGBS compared with OPC at all the current densities.

The galvanic current monitoring was conducted for up to 100 days and terminated where corrosion initiation was observed [12]. Generally, the passive film can be interpreted as being broken when the current density increases sharply through 1-2 $\mathrm{mA} / \mathrm{m}^{2}$. Hence in the present work, the corrosion initiation was defined as a time when the galvanic current density exceeds $2 \mathrm{~mA} / \mathrm{m}^{2}$ completely, taking into account the possibility of repassivation. The period required for corrosion initiation in OPC was 12, 34, 42, and 66 days when the applied current density was $0,250,500$, and $750 \mathrm{~mA} / \mathrm{m}^{2}$, respectively, as seen in Figure 2. In the case of mortar containing GGBS, the corresponding times were $9,40,60$, and 84 days with increasing applied current densities. For the control case, it seemed that GGBS did not have an influence on the durability of mortar because the content of chloride ions near the steel rebar was already over the chloride threshold level, ranging from $0.3 \%$ to $2.0 \%$ by weight of binder by blending $\mathrm{NaCl}$ of $3 \%$ with mixing. The corrosion initiation for GGBS was always later than OPC except for the untreated condition. Meanwhile, the higher the applied current density, the later the corrosion initiation regardless of binder type. Moreover, it was also notable that the galvanic current densities for GGBS showed sharp increments after corrosion initiation, compared with the stepwise trend of OPCs.

3.2. Corrosion Behaviour Depending on Binder Type and Current Density. The polarization resistance and open circuit potential measurement subjected to the applied current density in electrochemical treatment of 4 weeks were measured as seen in Figure 3. The polarization resistance for OPC varied about $1.82,4.67,23.58$, and $40.46 \Omega \cdot \mathrm{cm}$ at $0,250,500$, and $750 \mathrm{~mA} / \mathrm{m}^{2}$ of current density, respectively. When it comes to GGBS, the polarization resistance ranged about 3.35, 


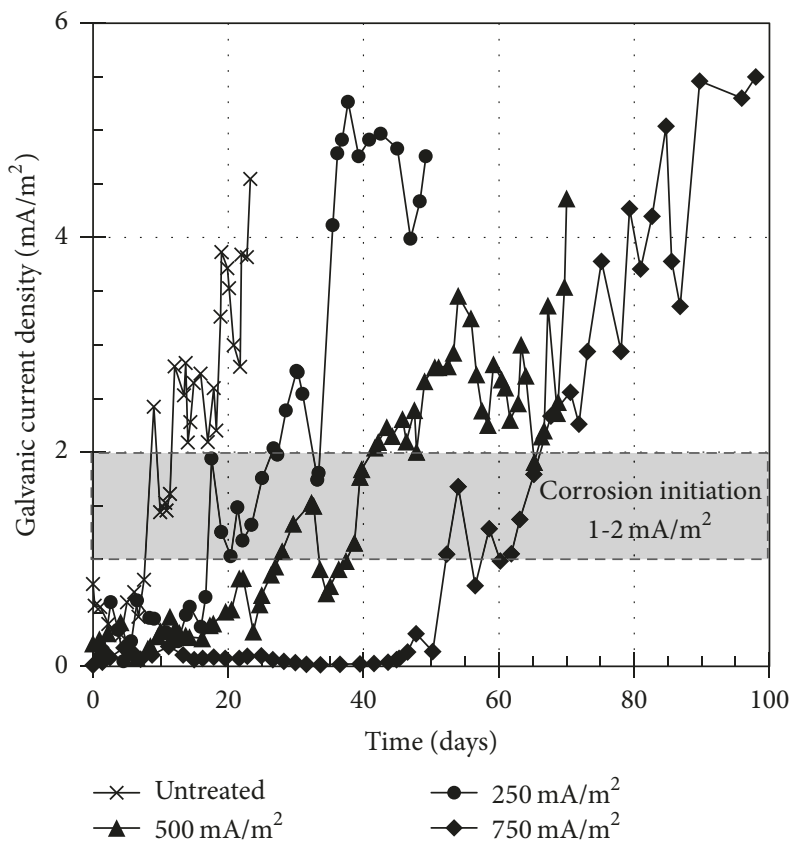

(a) OPC

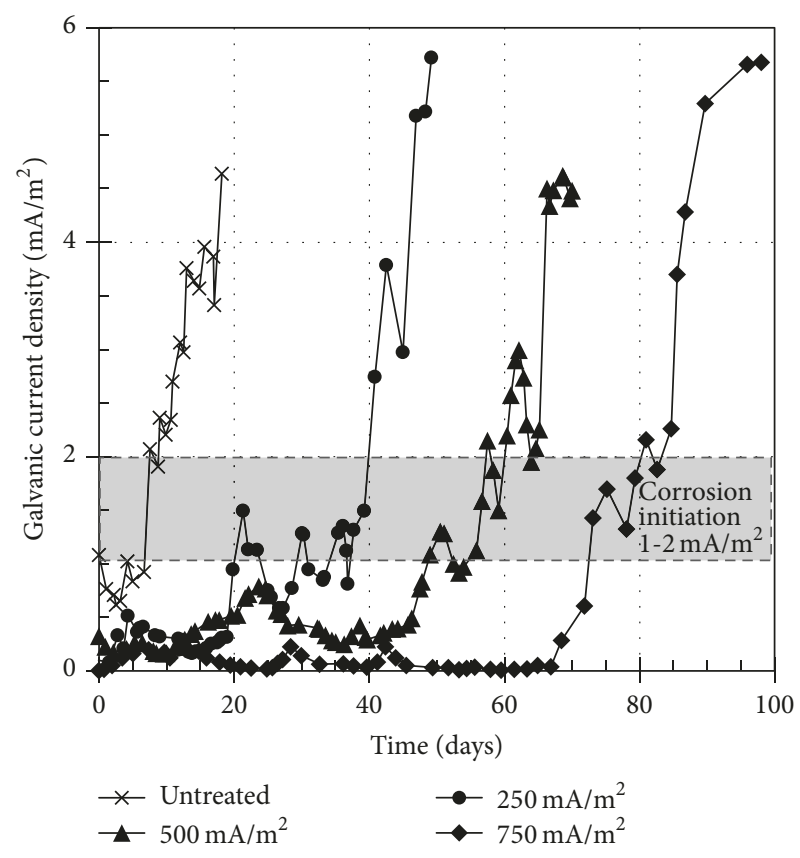

(b) $60 \%$ GGBS

Figure 2: Galvanic current densities of steel in concrete after electrochemical treatment of $0,250,500$, and $750 \mathrm{~mA} / \mathrm{m}^{2}$ for 4 weeks depending on OPC (a) and GGBS (b).

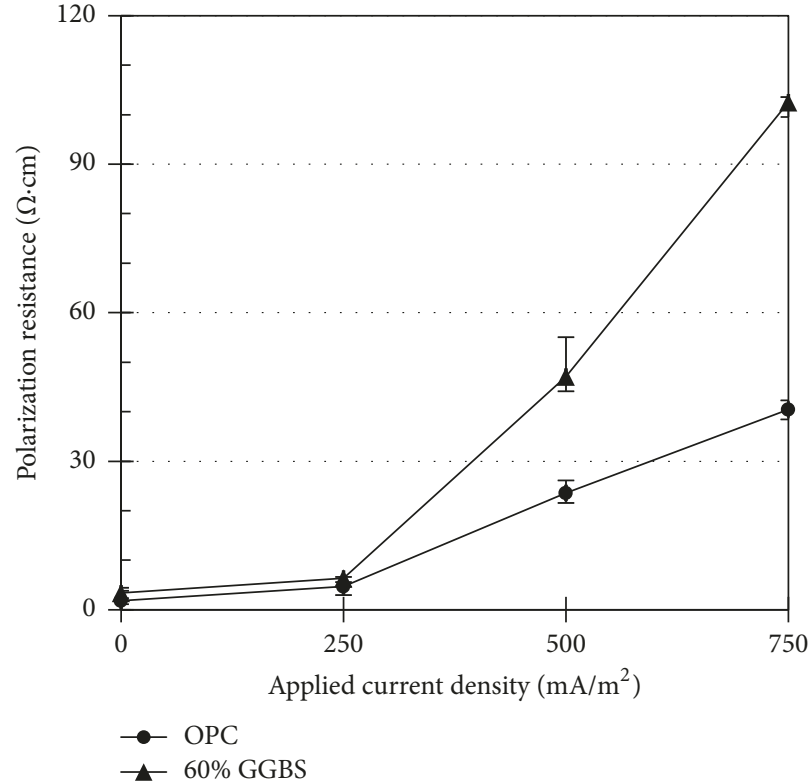

(a) Polarization resistance

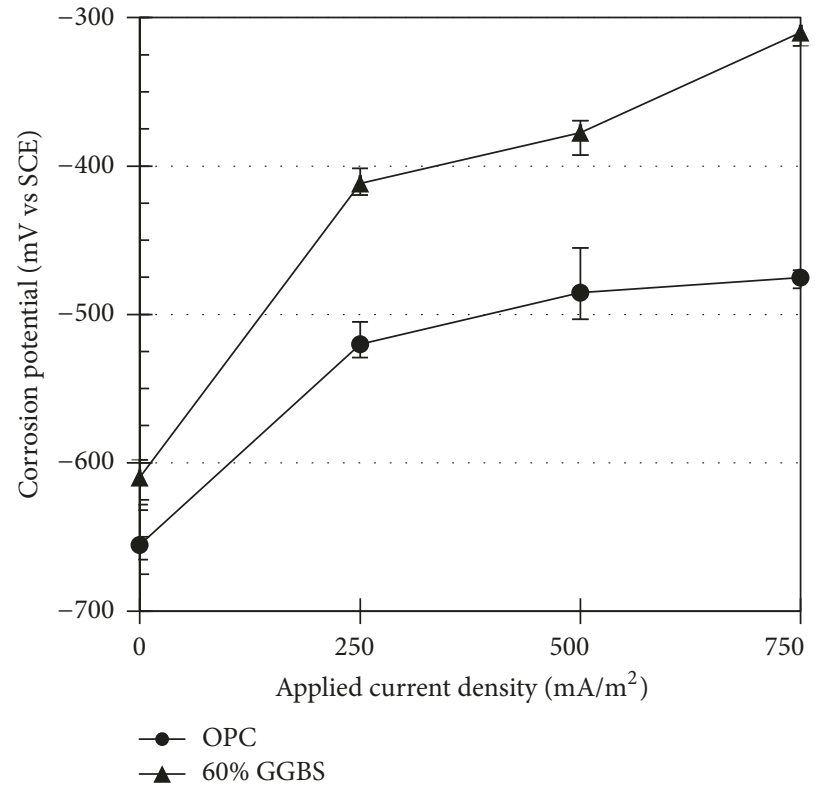

(b) Corrosion potential

FIGURE 3: Polarization resistance (a) and corrosion potential (b) in different concrete mix after electrochemical treatment at 250, 500, and $750 \mathrm{~mA} / \mathrm{m}^{2}$ for 4 weeks.

$6.32,47.08$, and $102.51 \Omega \cdot \mathrm{cm}$ depending on applied current density. The polarization resistance, which is in inverse proportion to corrosion rate regarding Ohm's law, can be interpreted in the state of steel rebar quantitatively in relation to how fast corrosion takes place on the steel surface. It can be known, therefore, that the corrosion rate was strongly dependent on the degree of electrochemical treatment; an increase in the applied current density always resulted in reduced corrosion rate. Simultaneously, for OPC, the corrosion potential untreated, which accounted for $-655 \mathrm{mV}$ 
TABLE 4: Average of mass loss of steel arising from corrosion after galvanic cell monitoring depending on the applied current density and binder type.

\begin{tabular}{lccccc}
\hline Binder type & & Mass loss (\%) & & \\
& Processing loss & Untreated & $250 \mathrm{~mA} / \mathrm{m}^{2}$ & $500 \mathrm{~mA} / \mathrm{m}^{2}$ & 0.33 \\
\hline OPC & \multirow{2}{*}{0.23} & 0.89 & 0.55 & 0.30 & 0.27 \\
$60 \%$ GGBS & & 0.79 & 0.48 & 0.27 \\
\hline
\end{tabular}

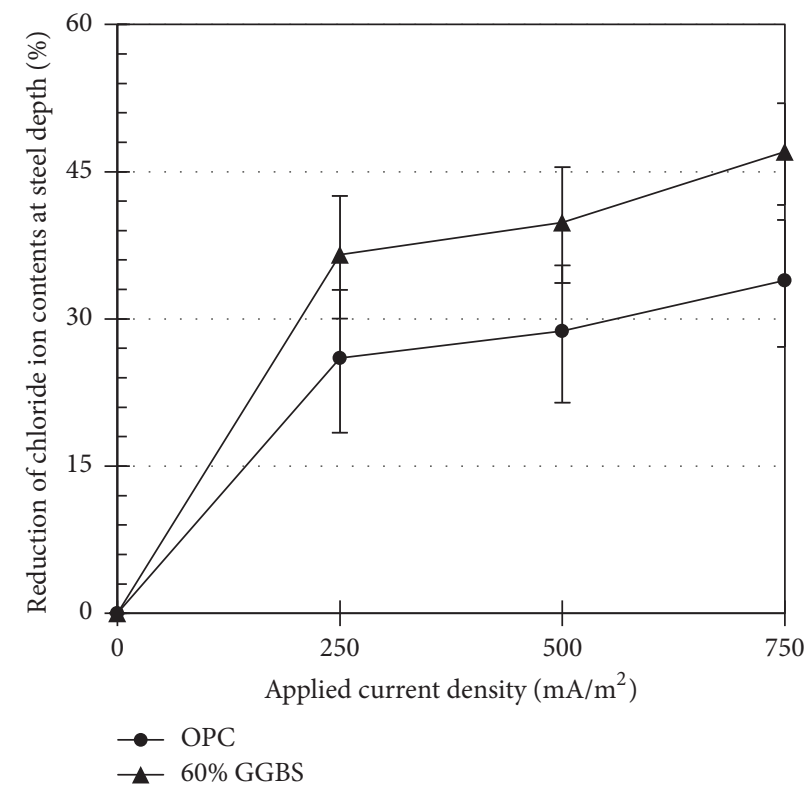

(a) Reduction of chloride contents

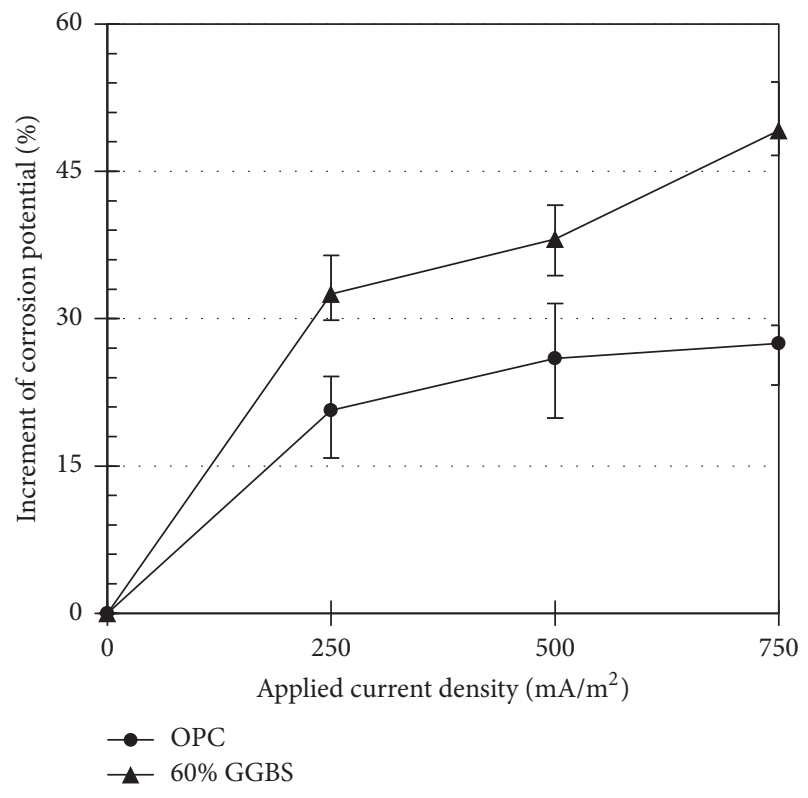

(b) Increment of corrosion potential

FIGURE 4: The reduction of chloride contents (a) and increment of corrosion potential (b) according to the applied current densities.

versus SCE, increased to $-520,-485$, and -475 at equivalent current densities in the electrochemical treatment, while the corrosion potential for GGBS was enhanced from -610 to $-412,-377$, and $-310 \mathrm{mV}$ versus SCE. The open circuit potential, called corrosion potential, in the present study is the voltage difference between the steel embedded in mortar and the reference electrode, which indicates the possibility of corrosion on the surface of steel; the higher the corrosion potential, the lower the probability of corrosion. In the same sense, it is evident that the higher polarization resistance and corrosion potential, when the current density was applied, signified the mitigation of steel corrosion; furthermore, the reduction of corrosion risk was more remarkable at GGBS mix than OPC.

The rust of steel rebars, obtained from the specimens by crushing at the end of galvanic current monitoring, was removed by cleaning and brushing in the acid solution. The average values of mass difference of steel rebar before/after corrosion are given in Table 4 including the processing loss, expressed by the percentage of mass loss to the original mass of steel rebar. It was shown that an increase in the applied current density resulted in a decrease in the mass loss of steel; in other words, the mass loss strongly depends on the applied current density. GGBS also lowered the mass loss from chloride-induced corrosion slightly than OPC. It was evident, however, that the corrosion for all of the steel embedded in mortar specimens occurred according to all of the mass loss exceeding the processing loss, meaning that those are visible in spite of the significant influences of applied current density and GGBS in repassivation.

3.3. Effect of Chloride Removal on Corrosion Behaviour. The reduction of chloride contents at the vicinity of steel of nontreated specimen and the increase of corrosion potential depending on the applied current densities are given in Figure 4. The reduction ratio of chlorides for OPC was $26.0,28.8$, and 33.0 at the current density of 250,500, and $750 \mathrm{~mA} / \mathrm{m}^{2}$, respectively; meanwhile, it was $36.6,39.8$, and 47.0 at the identical current density for GGBS. The efficiency of electrochemical treatment for GGBS was anticipated to be worse than OPC due to the higher binding capacity, whereas the results showed the reversed tendency. The difference between expectation and practice was attributed to binding mechanism presumably, divided into physical and chemical process. Physical binding resulted from the adsorption of chloride ions on the surface of the C-S-H hydrates in the cement matrix by electrostatic or Van der Waals forces between charged particles. In a case of chemical binding, the formation of Friedel's salt, having immobility, is accomplished through ion exchange mechanism meaning 


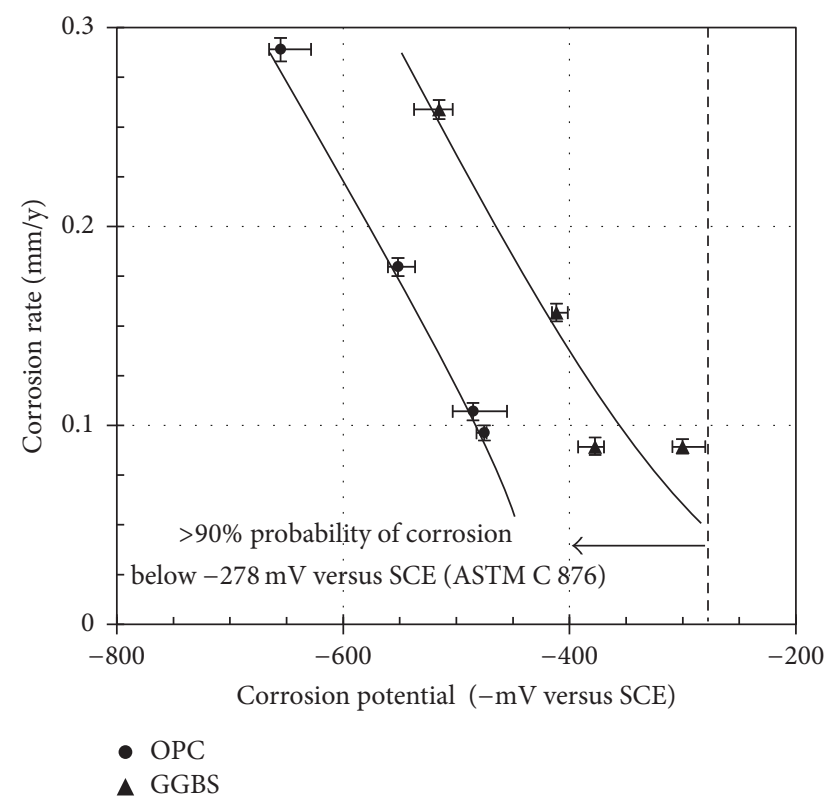

FIGURE 5: Corrosion rate calculated by mass loss of specimens with high corrosion potential.

absorption or the reactions of $\mathrm{C}_{3} \mathrm{~A}$ and $\mathrm{C}_{4} \mathrm{AF}$ among clinkers with chlorides during hydration $[6,13]$. The bound chlorides physically can be dissolved to chloride ions under electrochemical treatment; on the contrary the chemical bound chlorides are still immobile and not removed as crystalline salt form. It is regarded, therefore, that the reduction of chloride contents in mortar for GGBS mix was more remarkable due to the physical bound chloride accounting for the high proportion of total bound chloride, even though the chloride binding capacity for GGBS is superior to OPC. However, a ratio of physical and chemical binding for each binder was not mentioned in the present study. The relationship between the chloride contents and the corrosion potential can be deduced from the similar trend of results varying with the magnitude of the current, where the probability of corrosion is strongly dependent on the concentration of chloride ions. It seemed that the corrosion potential rose with the decrease of corrosion probability because the steel rebar was stabilized depending on the amount of chloride ions existing, which are aggressive ions for corrosion, at the vicinity of steel.

\subsection{Relationship between Corrosion Potential and Corrosion} Rate. It is given that the prevailing corrosion potential trend of the corrosion rate is based on real corrosion in Figure 5. The corrosion rate was calculated from mass loss measured after galvanic current monitoring though Faraday's law. It was notable that the lower corrosion potential steel has the higher corrosion rate which occurred for each binder type. The similar galvanic current density of $4.5-6 \mathrm{~mA} / \mathrm{m}^{2}$ between all cases implies that the steel corrosion already initiated, as indicated in Figure 2, attributed more corrosion which resulted during an identical period at the lower corrosion potential to the earlier onset of corrosion. When it comes to the critical corrosion potential having to be the onset of corrosion, which is defined as $-278 \mathrm{mV}$ versus SCE [14], the corrosion potential measured after electrochemical treatment for all specimens was still lower than threshold values indicating the onset of corrosion. Inevitably, the corrosion occurred within the corrosion monitoring of 100 days at all specimens according to the corrosion probability over $90 \%$. Consequently, the applied current density, which is varied between 250 and $750 \mathrm{~mA} / \mathrm{m}^{2}$ to perform the electrochemical chloride extraction, could not fully achieve protection of the steel in chloride contaminated mortars from corrosion. Furthermore, it is pointed out that the corrosion rate of GGBS mix was higher than OPC mix having the same corrosion potential, although the GGBS was evaluated to mitigate corrosion far more under electric field due to binding capacity and binding mechanism. Hence, it is crucial that GGBS is exposed to further corrosion risk at the similar corrosion potential compared with OPC, even though GGBS shows better durability than OPC under the same environment or the identical treatment condition.

\section{Conclusion}

The influence of electrochemical treatment on mortar contaminated by $3 \%$ chlorides related to the binder in the form of $\mathrm{NaCl}$ was identified experimentally by evaluating corrosion behaviour and the content of chlorides at the vicinity of steel rebar embedded. All of the specimens, which were divided into two groups for each purpose, were treated identically till the end of electrochemical treatment. OPC and $60 \%$ GGBS were used to investigate the benefit of mix design and the current density was applied to the mortar ranging $250-750 \mathrm{~mA} / \mathrm{m}^{2}$ in relation to the surface of unprotected steel for 4 weeks to mimic the electrochemical chloride extraction. The conclusion derived experimentally from this present study is given as below:

(1) Chloride profiles and the galvanic current monitoring of 100 days after measuring the corrosion performance were conducted simultaneously to identify the benefit of electrochemical treatment for corrosion initiation. It is notable that electrochemical chloride extraction affected more removal of chlorides at the vicinity of steel with an increase of applied current density. Furthermore, in galvanic current cell monitoring, the corrosion was initiated at $12,34,42$, and 66 days for OPC when the applied current density was $0,250,500$, and $750 \mathrm{~mA} / \mathrm{m}^{2}$, respectively; meanwhile, the initiation of corrosion for GGBS was 9, 40,60, and 84 days at identical applied current density; an increase in the concentration chloride extracted from treatment resulted in an increase in a period of passivation of steel. For untreated condition, it seemed that GGBS did not have an effect on the onset of corrosion because the content of chlorides at the depth of steel in the mortar was already over the chloride threshold level.

(2) The corrosion behaviour, including polarization resistance, open circuit potential, and mass loss, was evaluated at the end of electrochemical treatment. The 
polarization resistance and the corrosion potential of rebar in a salt contaminated mortar were enhanced when current density was applied; in other words, electrochemical treatment reduced the corrosion rate and probability of corrosion. When it comes to mass loss, it was also shown that an increase in the applied current density resulted in a decrease in the mass loss of steel and GGBS lowered the mass loss from chloride-induced corrosion than OPC.

(3) The influence of electrochemical chloride extraction was dependent on binder type in mix due to mechanism of chloride binding. The reduction ratio of chlorides for OPC and GGBS was 33\% and 47\%, respectively, at the highest current density of $750 \mathrm{~mA} / \mathrm{m}^{2}$. This result was attributed presumably to a lower chemical immobilization of chlorides in GGBS mix, of which physical binding mechanism accounts for the high proportion of total bounded chlorides. The reduction of chloride contents in mortar for GGBS mix was more remarkable because more chloride ions adsorbed on the surface of hydrates in GGBS were decomposed into free ions having mobility than OPC. Consequently, the increase of corrosion potential for GGBS was more significant than OPC according to the steel rebar becoming stabilized depending on the amount of chloride ions existing at the depth of steel.

(4) When the corrosion rate calculated by the erosion of steel and the corrosion potential measured at the end of the electrochemical treatment were compared, all of the steel could not be repassivated completely, although the benefit of electrochemical treatment was more remarkable in GGBS than OPC. It seems that corrosion damage is more fatal in GGBS than OPC at the same corrosion potential, while GGBS has superior corrosion performance compared to OPC under the same environment and treatment conditions. Therefore, it should be conducted prudently to evaluate corrosion state depending on binder type.

\section{Conflicts of Interest}

The authors declare that they have no conflicts of interest.

\section{Acknowledgments}

This research was supported by a grant from Technology Advancement Research Program funded by Ministry of Land, Infrastructure and Transport of Korean government (no. 15CTAP-C097546-01).

\section{References}

[1] K. Thangavel, S. Muralidharan, V. Saraswathy, M. A. Quraishi, and K. Y. Ann, "Migrating vs admixed corrosion inhibitors for steel in portland, pozzolona and slag cement concretes under macro cell condition," Arabian Journal for Science and Engineering, vol. 34, no. 2C, pp. 81-93, 2009.

[2] J. P. Hwang, H. B. Shim, S. Lim, and K. Y. Ann, "Enhancing the durability properties of concrete containing recycled aggregate by the use of pozzolanic materials," KSCE Journal of Civil Engineering, vol. 17, no. 1, pp. 155-163, 2013.

[3] M. D. A. Thomas and P. B. Bamforth, "Modelling chloride diffusion in concrete effect of fly ash and slag," Cement and Concrete Research, vol. 29, no. 4, pp. 487-495, 1999.

[4] S.-W. Pack, M.-S. Jung, H.-W. Song, S.-H. Kim, and K. Y. Ann, "Prediction of time dependent chloride transport in concrete structures exposed to a marine environment," Cement and Concrete Research, vol. 40, no. 2, pp. 302-312, 2010.

[5] R. K. Dhir, M. A. K. El-Mohr, and T. D. Dyer, "Chloride binding in GGBS concrete," Cement and Concrete Research, vol. 26, no. 12, pp. 1767-1773, 1996.

[6] H. W. Song, C. H. Lee, M. S. Jung, and K. Y. Ann, “Development of chloride binding capacity in cement pastes and influence of the $\mathrm{pH}$ of hydration products," Canadian Journal of Civil Engineering, vol. 35, no. 12, pp. 1427-1434, 2008.

[7] K. Y. Ann and H.-W. Song, "Chloride threshold level for corrosion of steel in concrete," Corrosion Science, vol. 49, no. 11, pp. 4113-4133, 2007.

[8] K. B. Kim, J. P. Hwang, and K. Y. Ann, "Influence of cementitious binder on chloride removal under electrochemical treatment in concrete," Construction and Building Materials, vol. 104, pp. 191-197, 2016.

[9] V. Bouteiller, C. Cremona, V. Baroghel-Bouny, and A. Maloula, "Corrosion initiation of reinforced concretes based on Portland or GGBS cements: Chloride contents and electrochemical characterizations versus time," Cement and Concrete Research, vol. 42, no. 11, pp. 1456-1467, 2012.

[10] J. J. Chang, "A study of the bond degradation of rebar due to cathodic protection current," Cement and Concrete Research, vol. 32, no. 4, pp. 657-663, 2002.

[11] J. S. Reou and K. Y. Ann, "The distribution of hydration products at the steel-concrete interface for concretes subjected to electrochemical treatment," Corrosion Science, vol. 52, no. 6, pp. 2197-2205, 2010.

[12] J. S. Reou and K. Y. Ann, "Electrochemical assessment on the corrosion risk of steel embedment in OPC concrete depending on the corrosion detection techniques," Materials Chemistry and Physics, vol. 113, no. 1, pp. 78-84, 2009.

[13] H. Zibara, Binding of external chlorides by cement pastes [Ph.D. thesis], University of Toronto, Toronto, Canada, 2001.

[14] ASTM, Standard Test Method for Corrosion Potentials of Uncoated Reinforcing Steel in Concrete, ASTM C 876, ASTM International, 2009. 

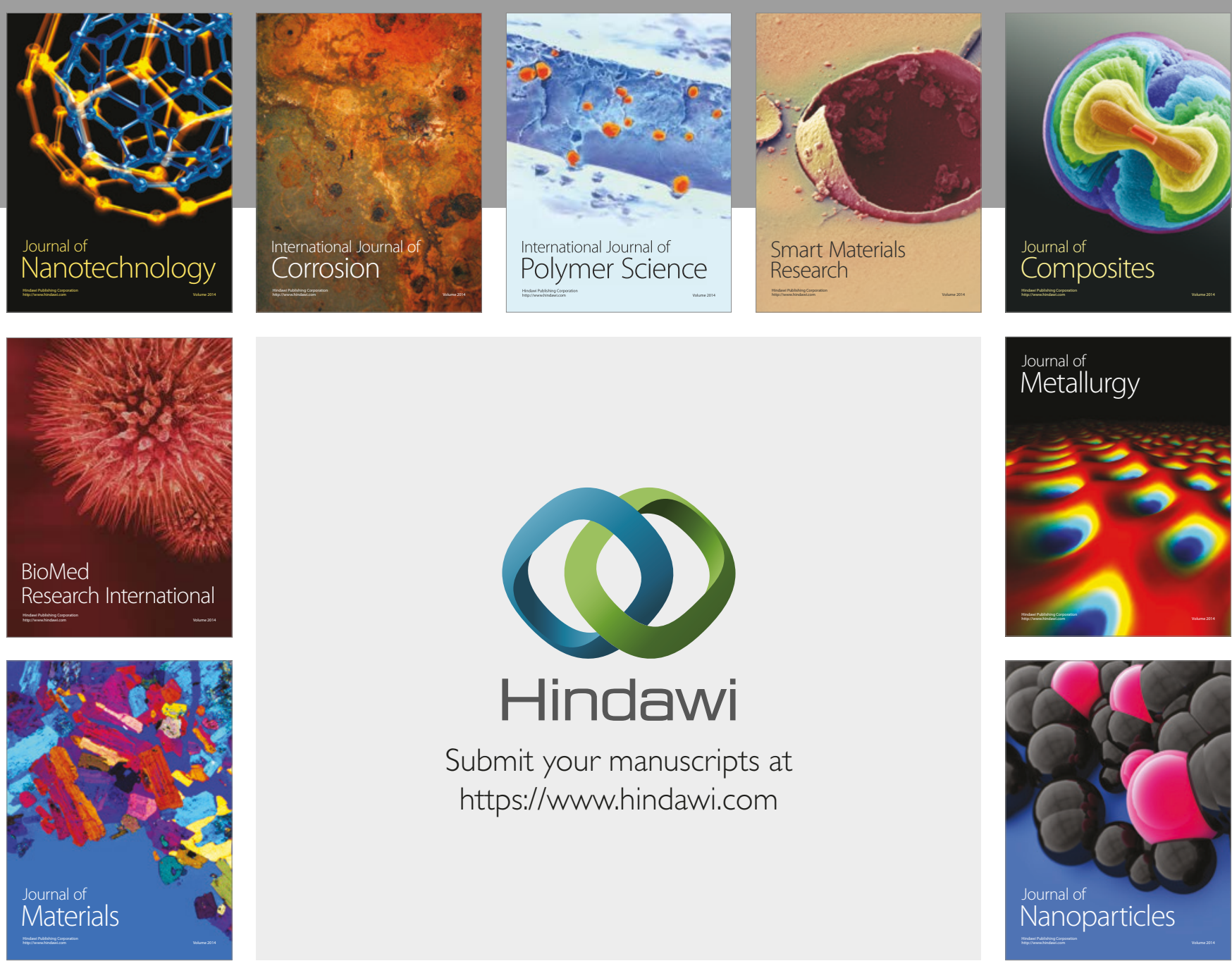

\section{Hindawi}

Submit your manuscripts at

https://www.hindawi.com
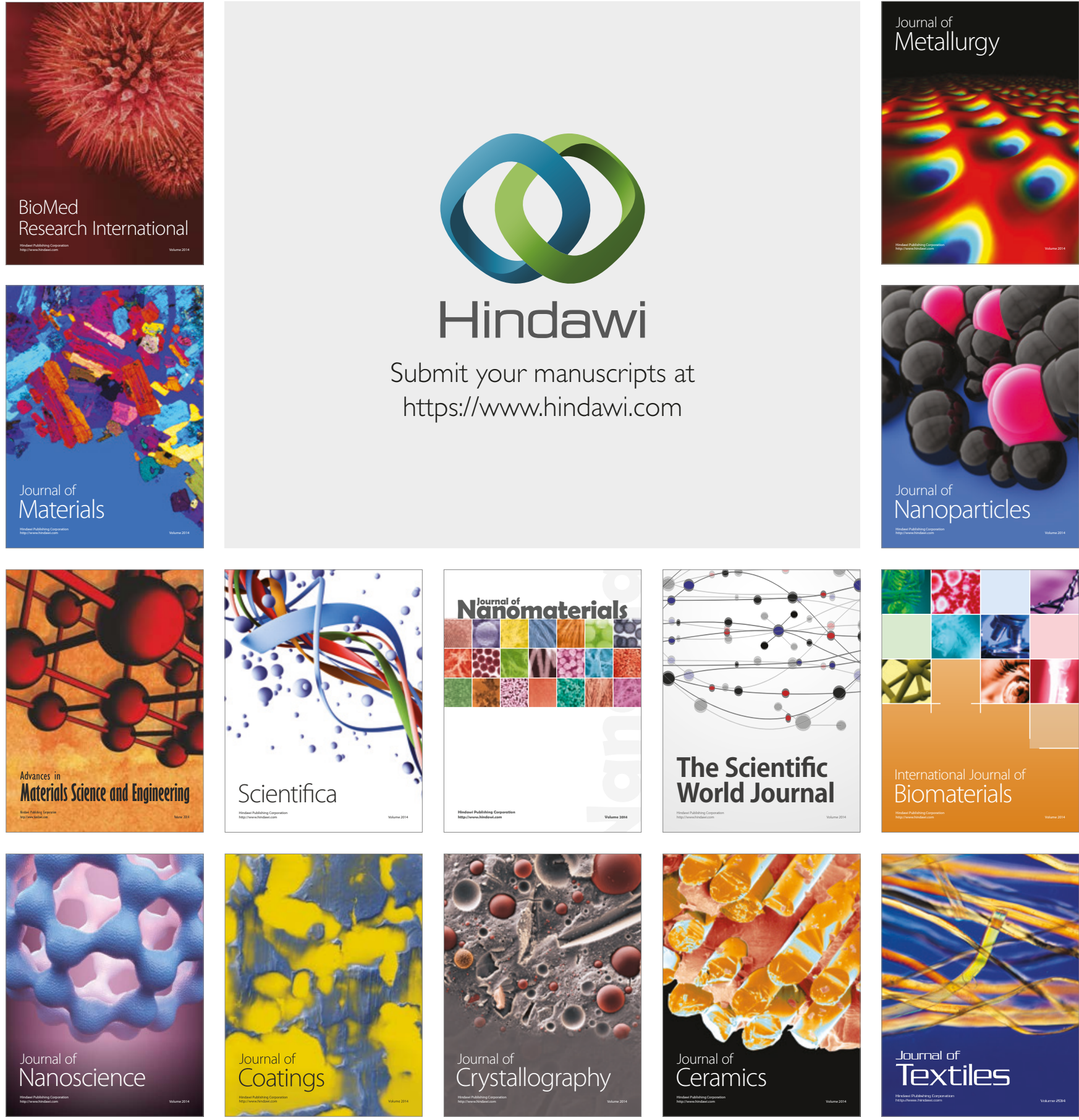

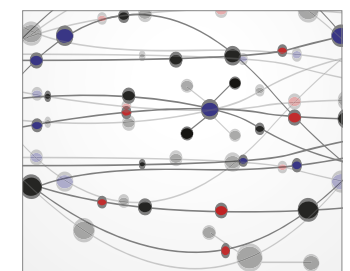

The Scientific World Journal
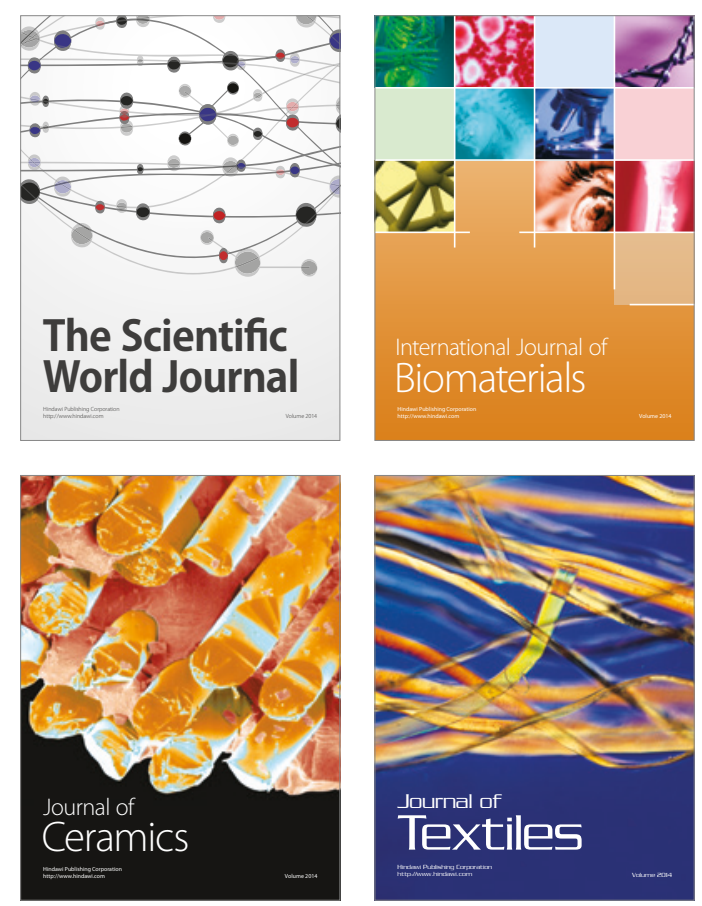